Orbis Tertius, vol. XXII, $n^{\circ}$ 25, e043, junio 2017. ISSN 1851-7811

Universidad Nacional de La Plata

Facultad de Humanidades y Ciencias de la Educación

Centro de Estudios de Teoría y Crítica Literaria

\title{
Terry Eagleton, Cómo leer literatura.
}

Buenos Aires, Ariel, 2016, 242 páginas.

\section{Valeria Sager}

En La larga Revolución, Raymond Williams escribe que la novela realista pasó de moda junto con el cabriolé, inmediatamente asume que en las novelas modernas los criterios del realismo aún son válidos. Cómo leer literatura de Terry Eagleton tiene un punto de partida similar: "Igual que la danza folklórica irlandesa —escribe - el arte de analizar obras literarias está en las últimas” (p. 11). Mientras que la afirmación de Williams se relativiza para admitir la persistencia del realismo, Eagleton arroja su provocación sin mayores especificaciones y la deja flotando con la misma fuerza de verdad con la que la enuncia. Si aceptamos que el arte de analizar obras literarias es una práctica perimida, en todo caso vuelve del pasado en cada texto y en cada clase que sin considerar su fin, emprende la lectura con el deseo de la teoría, un deseo que podría traducirse en la búsqueda de abstracción y de asociación, practicadas desde una perspectiva que persigue un modo de construir pasajes entre conceptos y casos. Es cierto que ya no hay muchos críticos que sin limitarse a un corpus pequeño y sin abordar solo los nombres o las obras esperables de un campo de especialización, abarquen tantos ejemplos y tantos autores para intentar lo que Eagleton se propone: recuperar una disciplina que le parece correr peligro de extinguirse para siempre.

Eagleton se mueve en ese vaivén que, como las piruetas de la danza irlandesa, atraviesa el tiempo y se mete en un ritmo frenético. Si sus libros son una especie de demostración de lo que puede hacerse en una clase para que la teoría y los ejemplos se iluminen, lo que produce es un impulso por compartir lo que dice, lo que un buen crítico o un buen profesor sabe, lo que quiere enseñar y cómo hacerlo.

La sucesión de ejemplos que Cómo leer literatura articula con velocidad, como si el libro fuera una máquina enloquecida, parece ir abriendo un mundo laberíntico en el que cada recorrido es un poco más arriesgado que el anterior. El primer capítulo, "Comienzos”, es una interrogación sobre lo literario. Allí, lo que Eagleton exponía en las primeras páginas de Una introducción a la teoría literaria, esto es que puede considerarse a la literatura no tanto como una cualidad o conjunto de cualidades inherentes que quedan de manifiesto en cierto

Cita sugerida: Sager, V. (2017). [Revisión del libro Cómo leer literatura por Terry Eagleton]. Orbis Tertius, $22(25)$, e043. https://doi.org/10.24215/18517811e043 
tipo de obras, sino como la convivencia de las diferentes formas en que la gente se relaciona con lo escrito, vuelve a aparecer para aceptar, primero, y como punto de partida, la mirada formalista. La premisa de que las obras literarias son construcciones retóricas y que por lo tanto el tono, la cadencia, la sintaxis, la estructura las constituyen, deja ver a continuación su revés. Lo que Eagleton señala entonces, es que si nos conformamos con esa perspectiva y prestamos atención solo a los procedimientos propios del lenguaje utilizado, podríamos leer también de modo literario un informe sobre la erosión del suelo en Nebraska. Como en Una introducción a la teoría literaria, no se trata tampoco aquí de encontrar una definición positiva o final de lo que es la literatura. Se trata, más bien, de registrar cómo leer eso que aun fuera de toda tesis sobre su ser, reconocemos como literario. Se trata de explicar de qué modo esa identificación nos lleva a leer ciertas regularidades y rupturas. En ese sentido, el primer capítulo busca y colecciona las particularidades de una serie de comienzos, Pasaje a la india de Forster, la Biblia, Orgullo y prejuicio de Austen, Moby Dick de Melville; algunos poemas de Keats, Philip Larkin, Emily Dickinson; y en el teatro, Macbeth, Esperando a Godot. Si busca mirar esos textos desde una perspectiva crítica que se detiene en la “elevada sensibilidad al lenguaje”, la textura sonora, las ambigüedades significativas, la manera de utilizar la sintaxis; pasa en el capítulo siguiente a lo que llama "asuntos mayores”: el personaje, la trama, la narrativa. Es que lo que Cómo leer literatura sostiene como tensión central de todo lo que dice es la oposición que en esos dos primeros capítulos se exhibe como decisiva. Si no hay en el libro una definición absoluta de la literatura, podría ser porque en realidad la literatura no es una cosa sino dos. Un conjunto de textos en los que puede registrarse una elevada sensibilidad al lenguaje y un conjunto de lectores y modos de leer que buscan esa sensibilidad pero también, lo que se teje en torno a un personaje, una voz, una mirada y una acción, aquello que alcanzaría para exponer lo literario de la literatura en una línea que fuera desde Aristóteles al estructuralismo y aquello, por supuesto, que tan claramente sostuvo Georg Lukács como la línea divisoria determinante que señala la distancia entre narrar y describir.

En el segundo capítulo, "El personaje”, la tensión a la que nos referimos empieza a desplegarse y aunque con valoraciones menos ostensibles se ordena, del mismo modo que en Lukács, en dos grandes sistemas, el del Realismo y el del Modernismo. Uno de los logros de la gran novela realista europea, escribe Eagleton, consiste en la interconexión entre personaje y contexto. La novela realista se aferra a vidas individuales en términos de historias, comunidades, relaciones e instituciones. En la novela modernista, en cambio, el personaje se nos presenta con una sola conciencia solitaria. En el Realismo, el personaje tiende a ser bastante estable y unificado, la identidad parece un aspecto poco problemático y puede observarse una evolución coherente. En el Modernismo, lo que vemos es todo lo contrario. Allí -en Ulises de Joyce o en Esperando a Godot de Beckett — incluso resulta difícil determinar si sucede algo o no y lo que se advierte más bien es el cuestionamiento de la idea imperante de personaje. El concepto de yo del Modernismo pertenece "a un reino del ser oscuro, primigenio y profundamente impersonal. Y ése es un terreno que los autores realistas preferirían no tener que pisar” (p. 82). Esa disolución, el desmembramiento del personaje y del yo, exhiben que el verdadero protagonista de gran parte de las obras modernistas, no es un personaje u otro sino el lenguaje utilizado.

En el capítulo 3 titulado "Narrativa”, se señala que para el Realismo clásico, el mundo está moldeado de acuerdo con la historia y que en el Modernismo no existe ningún orden aparte del que nosotros nos construimos. Como el orden es arbitrario también los son el inicio y el desenlace de la ficción, por lo tanto en el Modernismo "la idea de narrativa entra en crisis" (p. 123). Como se ve y aunque no aparezca enunciado de este modo, ni como estructura que ordene el índice del libro, la literatura y también el cómo leerla, parecen definirse en la tensión entre la perspectiva del Realismo y la del Modernismo, si en la primera puede señalarse un verdadero comienzo de la historia y un verdadero final, una trama fácilmente narrable y un personaje o un conjunto de personajes estables; en la segunda, nada de esto es tan sencillo. 
Hasta aquí, la serie de definiciones parece recurrir a un universo conceptual en miniatura, aunque lo hace de modo magistral y lo agiganta con la casi infinita exhibición de casos; compila lo que ya sabemos. Nociones, sistemas, puntos de vista sobre los que ya hemos leído mucho y que más allá de ese modo fabuloso de exposición — pienso aquí en lo fabuloso como adjetivo vinculado a quien narra y describe como si contara una fábula—, todos conocemos. Hay dos aspectos que en el libro entusiasman y se destacan con nitidez. Son también dos aciertos. El primero podría identificarse como una vocación ontológica que gira alrededor de lo que existe y lo que es posible. La intensidad con la que eso se interroga se vuelve por momentos tan exagerada que, al borde de la hilaridad, nos lleva a cuestionar algunas categorías y presupuestos como si nos enfrentáramos con ellos por primera vez y tuviéramos que mirarlos como objetos absolutamente desconocidos. Así, cuando los ejemplos tocan el borde de lo absurdo, revelan un carácter novedoso que nos hace pensar varios problemas de la literatura a partir de cero. Las vueltas de tono filosófico que giran alrededor de lo que existe y lo que es posible, van hilando la trama del análisis. Si definir qué es la literatura y cómo leerla, ya es de por sí complicado, cuando Eagleton se pone a hacer pruebas de realidad o de posibilidad de existencia de aquello que explica, el camino sinuoso de la exposición se vuelve cómico e insondable pero también, como decíamos, adquiere una inocencia compleja que nos hace pensar de nuevo lo que creíamos transparente. Cuando en el capítulo sobre el personaje, opone el modo de su aparecer en el Realismo y en el Modernismo, se detiene en la imposibilidad de la individualización absoluta y lo hace otra vez con un ejemplo irrisorio: "Sólo podemos identificar los objetos en el lenguaje, y el lenguaje es general por naturaleza [...]. No hay ninguna palabra especial para mis cejas o para mis enfados [...]. De hecho, no hay nada que no se parezca a otra cosa en algún aspecto. La Gran Muralla de China se parece al concepto de angustia en el sentido que ninguna de las dos cosas sirve para pelar un plátano” (p. 72).

Pero dijimos que los aciertos del libro son sobre todo dos. Por momentos Cómo leer literatura se concentra en la lectura crítica de algunas obras de un modo luminoso y bello. En el capítulo "Narrativa”, al análisis de cómo se construye la mirada del narrador en David Copperfield de Dickens, de cómo pesa la presencia de lo material en Defoe; el estudio de la configuración del lenguaje y de las imágenes en El corazón de las tinieblas pero sobre todo el extenso y brillante análisis de Grandes esperanzas que incluye, además un pasaje por lo que de la novela de Dickens hay en Harry Potter, hacen de ese capítulo un verdadero compendio de ejercicios críticos agudos y precisos. La comparación entre el modo de escribir de Defoe en el que el lenguaje parece un mero instrumento y el de James en el capítulo 4, y todo lo que en ese capítulo titulado “Interpretación”, hace a las posibilidades y los límites de un lenguaje cuya característica es la de no tener contexto y la de no transmitir una experiencia más que la que está expuesta en el propio lenguaje, se definen de un modo tan claro que todo el libro parece volver a enfocarse.

Finalmente, el último capítulo "Valor” despliega algo que se dice antes. En el anteúltimo, "Interpretación”, Eagleton se pregunta si puede existir una lectura convincente con la que nadie haya dado hasta el momento, o con la que nadie llegue a dar nunca y responde, “¿Por qué no?” (p. 166). En ese sentido es que respecto de la explicación acerca de cómo el valor de la literatura cambia a lo largo de la historia, en el final se detiene en la obra de William McGonagall, poeta escocés del siglo XIX, cuyo mérito indiscutible, según dice, es ser considerado por consenso uno de los escritores más atroces que hayan blandido una pluma sobre un papel, “¿podemos descartar completamente — se pregunta— la posibilidad de que algún día McGonagall llegue a ser considerado uno de los más grandes poetas de la historia?” (p. 227). Las obras literarias, dice antes, son transacciones, no objetos materiales (p. 165). La literatura parece ser la ocasión de inventar ocurrencias y ejemplos para abrir la pregunta por lo que aun no sucedió, la lectura por venir. Emma Woodhouse - escribe en "El personaje_-", la heroína de Jane Austen, sólo existe mientras alguien lee el libro (p 60); la literatura es para Eagleton una transacción. Algo que, dudoso, ambiguo, a veces inexistente vuelve a existir cada vez que alguien piensa en ello. 